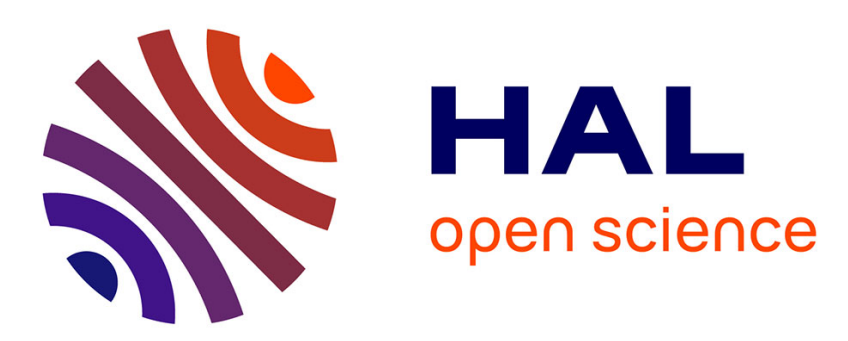

\title{
Piezo-tunneling strain sensors integrated on plastic by combining vacuum thin film coatings and $3 \mathrm{D}$ printing technologies
}

\author{
Rémi Rafael, Etienne Puyoo, Christophe Malhaire
}

\section{To cite this version:}

Rémi Rafael, Etienne Puyoo, Christophe Malhaire. Piezo-tunneling strain sensors integrated on plastic by combining vacuum thin film coatings and 3D printing technologies. Microsystem Technologies, 2020, 10.1007/s00542-020-04832-7 . hal-03344465

\section{HAL Id: hal-03344465 \\ https://hal.science/hal-03344465}

Submitted on 15 Sep 2021

HAL is a multi-disciplinary open access archive for the deposit and dissemination of scientific research documents, whether they are published or not. The documents may come from teaching and research institutions in France or abroad, or from public or private research centers.
L'archive ouverte pluridisciplinaire HAL, est destinée au dépôt et à la diffusion de documents scientifiques de niveau recherche, publiés ou non, émanant des établissements d'enseignement et de recherche français ou étrangers, des laboratoires publics ou privés. 


\title{
Piezo-tunneling strain sensors integrated on plastic by combining vacuum thin film coatings and 3D printing technologies
}

\author{
Rémi Rafael, Etienne Puyoo* and Christophe Malhaire
}

Institut des Nanotechnologies de Lyon, Université de Lyon, INL UMR 5270, CNRS, INSA de Lyon, Villeurbanne F-69621, France

E-mail: etienne.puyoo@insa-lyon.fr

Keywords: flexible strain sensors, piezo-tunnel effect, $\mathrm{Al}_{2} \mathrm{O}_{3}$, atomic layer deposition, 3D printing, Fused Deposit Modeling

\begin{abstract}
There is a growing demand for the integration of sensor functions on flexible substrates for wearable electronics, robotics or medical monitoring. For this, it is necessary to develop strain gauges both sensitive and integrable at low cost with a low thermal budget. The gauge factor of metal/insulator/metal piezo-tunneling strain sensors is first measured as a function of applied current and polarity, for different electrode materials (Al, Pt or Pd) and insulator $\left(\mathrm{Al}_{2} \mathrm{O}_{3}\right)$ thicknesses. A maximum gauge factor of 90 is obtained with an $\mathrm{Al} / \mathrm{Al}_{2} \mathrm{O}_{3}(10 \mathrm{~nm}) / \mathrm{Al}$ junction and top electrode injection. Results are discussed based on the Fowler-Nordheim model and it is shown that the electron effective mass in $\mathrm{Al}_{2} \mathrm{O}_{3}$ most likely plays a major role in the observed mechano-sensitivity. Next, the feasibility of a low-pressure sensor demonstrator based on a 3D-printing process on a polymer substrate is shown with a sensitivity of $0.19 \mathrm{bar}^{-1}$ in the $0-450$ mbar range.
\end{abstract}

\section{Introduction}

Piezoresistive sensors are of major interest for the development of both wearable and conformable electronics industry sectors (Amjadi 2016). Flexible strain sensors integrating piezoresistive elements can indeed be used to develop tactile sensing functions (Park 2016), human motion and medical monitoring (Tolvanen 2018; Puyoo 2018; Kang 2014), and multirecognition functions ( $\mathrm{Su} 2016$ ). They can also be used in the field of robotics, aerospace engineering and transportation to develop lightweight plastic Micro-Electro-Mechanical Systems (MEMS) that can be conformably integrated on non-planar surfaces (Xiao 2008). Among the different approaches which have been proposed in literature these past few years, piezo-tunneling strain sensors give rise to gauge factors in the range of 10 to 300 which compete with that of monocrystalline silicon (standard for piezoresisitive MEMS) (Herrmann 2007; Schlike 2016; Jiang 2015; Puyoo 2017; Zhu 2015; Rafael 2017). The principle of piezo- 
tunneling strain sensor is based on the fact that the electrical resistance of a tunnel junction exponentially varies with its parameters (junction length, electron effective mass, barrier height). For example, when submitted to mechanical stress, the variation of the tunnel junction length implies an exponential variation of the tunnel resistance which gives rise to these high gauge factors. This concept has been first exploited with metallic nanoparticle assemblies in which the current is flowing by tunnel effect from nanoparticle to nanoparticle (Herrmann 2007; Schlike 2016; Jiang 2015; Puyoo 2017). This concept has been later used to advantage with single MOS (Metal Oxide Semiconductor) junctions (Zhu 2015) and more recently by our group with MOM (Metal Oxide Metal) junctions (Rafael 2017). The key advantage of MOM junctions as compared to MOS junctions is attributed to their elaboration process which requires a low thermal budget and which can be applied on a variety of substrates (e.g. flexible polymer substrates, back-end-of-line integration). In this work, piezo-tunneling MOM strain gauges based on $\mathrm{Al}_{2} \mathrm{O}_{3}$ oxide material are first studied and optimized on silicon platform with conventional vacuum thin film deposition techniques: e-beam evaporation and atomic layer deposition (ALD). Then, the optimized process is transferred to flexible polyimide substrates and combined with $3 \mathrm{D}$ printing technology to develop a pressure sensor on plastic.

\section{Optimization of MOM strain gauges}

Here, MOM vertical stacks were first elaborated in a cross-bar geometry (surface of $0.25 \mathrm{~mm}^{2}$ ) on oxidized silicon substrates (thermal oxide thickness of 500nm). As shown in Figure 1a, bottom and top electrodes were patterned at room temperature by electron beam assisted evaporation through solid shadow masks. In this study different bottom electrode materials were tested (Al, Pt and Pd) whereas the top electrode was kept in Al. The oxide thin film was an $\mathrm{Al}_{2} \mathrm{O}_{3}$ layer (10nm or $20 \mathrm{~nm}$ thick) deposited by $\mathrm{ALD}$ at $200^{\circ} \mathrm{C}$ from TMA (Trimethyl Aluminum) and $\mathrm{H}_{2} \mathrm{O}$ precursors (pulse and purge durations of $60 \mathrm{~ms}$ and $10 \mathrm{~s}$, respectively, for both precursors). Figure $1 \mathrm{~b}$ presents a typical $\mathrm{J}(\mathrm{E})$ characteristic (i.e. current density as a 
function of the applied electric field) obtained on a $\mathrm{Pt} / \mathrm{Al}_{2} \mathrm{O}_{3} / \mathrm{Al}$ stack. As previously shown for $\mathrm{Al} / \mathrm{Al}_{2} \mathrm{O}_{3} / \mathrm{Al}$ junctions (Rafael 2017), electron transport in the MOM structure can be attributed to Fowler-Nordheim (FN) tunneling mechanism. Note that this FN mechanism is also observed on $\mathrm{Pd} / \mathrm{Al}_{2} \mathrm{O}_{3} / \mathrm{Al}$ stacks. The strain sensitivity of the MOM junctions is tested using a cantilever deflection method according to the experimental procedure described in reference (Rafael 2017). A $725 \mu \mathrm{m}$ thick $\mathrm{Si}$ cantilever ( $4 \mathrm{~cm}$ long by $1 \mathrm{~cm}$ wide) integrating $3 \mathrm{MOM}$ cross-bar structures is clamped in a vice at one end while a variable deflection is applied at the other end by a motorized actuator. A constant voltage bias (typically between 3 and 10V) is applied on the MOM device while the current is measured as a function of time for different deflection levels. The gauge factor GF is defined here as the relative change of current divided by the longitudinal strain $\varepsilon$. It is calculated assuming that the strain $\varepsilon$ for a deflection level $\delta$ at a distance L from the clamping position is given by (Rafael 2017):

$\varepsilon=\frac{3 t_{s i}(L-\mathrm{x})}{2 L^{3}} \delta$

where $t_{S i}$ is the thickness of the Si cantilever and $\mathrm{x}$ the position of the MOM junction on the beam.

In a previous paper (Rafael 2017), we have demonstrated that the strain sensitivity in $\mathrm{Al} / \mathrm{Al}_{2} \mathrm{O}_{3} / \mathrm{Al}$ junctions not simply originates from pure geometrical effects but also from the variation of physical parameters under strain (i.e. barrier height and/or electron effective mass in $\mathrm{Al}_{2} \mathrm{O}_{3}$ ). In order to ascertain the precise influence of barrier height and effective mass on the mechano-sensitivity, we have performed a parametric study which is summarized in Figure 2. The gauge factors of 6 junctions with different bottom electrodes (Al, Pt or Pd) and different tunnel oxide thicknesses (10 and 20nm) were characterized as a function of the no-load current level. For each MOM device, two different gauge factors were extracted by injecting electrons respectively from bottom electrode (positive voltage bias with bottom electrode grounded) and top electrode (negative voltage bias with bottom electrode grounded). Gauge factors ranging 
from 30 to 90 are obtained over three decades of no-load current levels (from $10^{-10} \mathrm{~A}$ to $10^{-7} \mathrm{~A}$ ). From figure 2, the first main observation is that there is no significant influence of the nature of the injecting electrode (Al, Pd or Pt) on the measured gauge factor. Therefore, we believe that the mechano-sensitivity of the MOM junction mainly relies on the intrinsic properties of $\mathrm{Al}_{2} \mathrm{O}_{3}$ and not on the properties of the metal from which electrons are injected. The barrier height of the MOM junction corresponds to the difference between the work function (WF) of the injecting metal and the electronic affinity of $\mathrm{Al}_{2} \mathrm{O}_{3}$. According to Hölzl (1979), Al, Pd and Pt have significantly different WFs. As a result, the barrier heights associated to these three electrode materials should be different and should as well vary differently under strain. From this assumption, we conclude that the barrier height has not a significant influence on the mechano-sensitivity and that the electron effective mass in $\mathrm{Al}_{2} \mathrm{O}_{3}$ most likely plays a major role. The second main observation concerns the influence of the tunnel current direction on the gauge factor. Whatever the electrode material and no-load current level, the gauge factor is kept almost twice higher when electrons are injected from the top electrode as compared to an injection from the bottom electrode. In FN tunneling regime, the triangular barrier seen by the electrons has an effective thickness that is smaller than the actual thickness of the junction. In other words, the electrons do not tunnel through the same $\mathrm{Al}_{2} \mathrm{O}_{3}$ effective layer when the polarity of the junction is reversed. The variation under strain of the effective mass at the interfaces could be affected by the chemical composition of $\mathrm{Al}_{2} \mathrm{O}_{3}$. A composition gradient of $\mathrm{Al}_{2} \mathrm{O}_{3}$ due to interdiffusion phenomena or electrode deposition processes could explain these different gauge factors observed with the two polarities. The last observation from figure 2 concerns the slight decrease of the gauge factor with respect to the no-load current level. This gauge factor variation is observed for all the junctions whatever the polarity. We believe that this tendency comes from the non-linearity of the FN tunneling current $I_{F N}$ model which is given by the following expression (Rafael 2017): 
$I_{F N}=\frac{S e^{2} m_{m}^{*}}{8 \pi m^{*} h \varphi} E^{2} \exp \left(-\frac{8 \pi \sqrt{2 m^{*} e} \varphi^{3 / 2}}{3 h E}\right)$

where $S$ is the surface of the MOM junction, e the elementary charge, $m_{m}^{*}$ the electron effective mass in the injecting metal, $m^{*}$ the electron effective mass in $\mathrm{Al}_{2} \mathrm{O}_{3}, h$ the Planck constant, $\varphi$ the barrier height and $\mathrm{E}$ the total electric field. From equation (2), we have calculated theoretical gauge factors by considering that the effective mass $m^{*}$ in $\mathrm{Al}_{2} \mathrm{O}_{3}$ varies under strain $\varepsilon$ while the barrier height $\varphi$ is kept constant. For this calculation, we have also considered that the thickness $t$ and the surface $S$ of the MOM junction both vary linearly with strain. The relative changes of thickness $t$ and surface $S$ with respect to the strain $\varepsilon$ are given by the two following equations:

$\frac{\Delta t}{t}=-\varepsilon v_{\mathrm{Al}_{2} \mathrm{O}_{3}}$

$\frac{\Delta S}{S}=\left(1-v_{S i}\right) \varepsilon$

where $v_{\mathrm{Al}_{2} \mathrm{O}_{3}}=0.22$ is the Poisson coefficient of $\mathrm{Al}_{2} \mathrm{O}_{3}$ and $v_{S i}=0.0625$ is the Poisson coefficient of monocrystalline $\mathrm{Si}$ on the $<110>$ axis.

A good agreement between theory and experiment is observed in Figure 2c for relative changes $\Delta m^{*} / m^{*}$ of $-0.17 \%$ and $-0.28 \%$ per $0.1 \%$ strain for bottom and top injections, respectively. This agreement confirms that the slight decrease of gauge factors with respect to the no-load current can be attributed to the non-linearity of the FN tunnel current model.

\section{Pressure sensor integrated on plastic}

Based on the piezo-tunneling strain gauges previously presented, an original approach for the realization of a pressure sensor on a polyimide (Kapton) substrate, with a 3D printed polylactic acid (PLA) rigid frame, is shown. A circular-shape diaphragm, $5 \mathrm{~mm}$ in diameter and $75 \mu \mathrm{m}$ thick (that of the Kapton substrate), was choosen as mechanical transducer. The strain gauges were first made on the front side of the substrate. Two laser-cut polysilicon shadow masks were used to define the layout of the bottom (same diameter as the future membrane) and top 
electrodes (Figure 3a and 3b). In fact, a total of seven redundant top electrodes were present (Figure 3c) but only one was measured at a time. The surface of each MIM junction was $0.25 \mathrm{~mm}^{2}$. Process steps are summarized in Figure 3d. A $100 \mathrm{~nm}$ thick palladium bottom electrode was evaporated through a first mask level. Then, a $10 \mathrm{~nm}$ thick $\mathrm{Al}_{2} \mathrm{O}_{3}$ film was deposited on the whole substrate by ALD. Finally, 100nm thick aluminum top electrodes were deposited through a second mask level. Both metals were deposited by electron beam evaporation.

Then, a Fused Filament Fabrication (FFF) 3D printer (MakerBot Replicator 2X) was used to grow a rigid frame, directly on the back side of the Kapton film, and define the membrane geometry (Figure 4). Printing parameters were: plate temperature of $100^{\circ} \mathrm{C}$; layer thickness of $0.2 \mathrm{~mm}$. Four PLA corners, one layer thick, were deposited on the plate. The Kapton film was placed in the middle, and attached to the plate by tape, before continuing the PLA filling. The four-pointed star shape ensured adherence of the PLA frame to the printer plate during process. In addition, small laser-drilled holes in the substrate form rivets to improve adhesion between Kapton and PLA. In order to limit residual stresses that may occur during cooling, the inside of the frame had a honeycomb structure (30\% filling). Despite this, an initial $100 \mu \mathrm{m}$ downwards deformation of the membrane was measured later without any applied pressure, so the printing process could probably be improved. A front view of a finished device, with its electrical connections, is given in the inset of Figure 5. The rear pressure chamber was connected to a pump through a manometer and a large buffer tank. Differential pressures were measured by means of a Fluke 718 pressure calibrator. Figure 5 shows, for one gauge, the relative current changes as a function of pressure. The non-linearity response of the gauge simply corresponds to the nonlinear load-deflection behavior of the membrane (large-deflection regime). From a linear fit between 0 and 450mbar, a 0.19 bar $^{-1}$ sensitivity was obtained. Although the sensitivity could be further increased by optimizing the design of our pressure sensor (membrane thickness, size and position of the gauge, Wheatstone bridge configuration...), we believe that this 
demonstrator opens the way to a new variety of conformable MEMS devices integrated on plastic. Future works will have to focus on the combination of 3D printing and LASER cutting processes in order to develop more complex MEMS structures like cantilever sensors, accelerometers or gyroscopes.

\section{Conclusion}

In summary, MOM junctions elaborated at low temperature $\left(\leq 200^{\circ} \mathrm{C}\right)$ by combining $\mathrm{ALD}$ and e-beam evaporation were first optimized on Si substrate. A maximum gauge factor of 90 was obtained with an $\mathrm{Al} / \mathrm{Al}_{2} \mathrm{O}_{3}(10 \mathrm{~nm}) / \mathrm{Al}$ junction and electron injection from the top electrode. This process was then transferred to polyimide substrate and combined with FFF process to develop a pressure sensor integrated on plastic showing a sensitivity of $0.19 \mathrm{bar}^{-1}$ in the 0 450mbar range.

\section{Acknowledgements}

Authors gratefully acknowledge facilities and technological staff's cooperation from NanoLyon platform.

\section{References}

Amjadi M, Kyung K-U, Park I and Sitti M (2016) Stretchable, skin-mountable, and wearable strain sensors and their potential applications: a review. Adv Funct Mater 26:1678. https://doi.org/10.1002/adfm.201504755

Choi Y W, Kang D, Pikhitsa PV, Lee T, Kim S M, Lee G, Tahk D and Choi M (2017) Ultrasensitive pressure sensor based on guided straight mechanical cracks. Scientific Reports 7:40116.

https://doi.org/10.1038/srep40116

Herrmann J, Muller K-H, Reda T, Baxter G R, Raguse B, de Groot G J J B, Chai R, Roberts M, and Wieczorek L (2007) Nanoparticle films as sensitive strain gauges. Appl Phys Lett 91: 183105.

https://doi.org/10.1063/1.2805026

Hölzl J and Schulte F K (1979) Work function of metals, in Solid surface physics, Springer, Tracts in Modern Physics, vol. 85, Springer, Berlin, Heidelberg. 
Jiang C-W, Ni I-C, Tzeng S-D, and Kuo W (2015) Nearly isotropic piezoresistive response due to charge detour conduction in nanoparticle thin films. Scientific Reports 5:11939.

https://doi.org/10.1038/srep11939

Kang D, Pikhitsa P V, Choi Y W, Lee C, Shin S S, Piao L, Park B, Suh K-Y, Kim T-i and Choi M (2014) Ultrasensitive mechanical crack-based sensor inspired by the spider sensory system. Nature 516:222.

https://doi.org/10.1038/nature14002

Park M, Park Y J, Chen X, Park Y-K, Kim M-S and Ahn J-H (2016) MoS 2 -based tactile sensor for electronic skin applications. Adv Mater 28:2556.

https://doi.org/10.1002/adma.201505124

Puyoo E, Malhaire C, Thomas D, Rafael R, R'Mili M, Malchère A, Roiban L, Koneti S, Bugnet M, Sabac A and Le Berre M (2017) Metallic nanoparticle-based strain sensors elaborated by atomic layer deposition. Appl Phys Lett 110:123103.

https://doi.org/10.1063/1.4978778

Puyoo E, Brottet S, Rafael R and Malhaire C (2018) Ultrahigh Sensitivity to Strain of Cracked Thin Films Based on Metallic Nanoparticles in a Dielectric Matrix. IEEE Sensors Letters 2(3):1-4.

https://doi.org/10.1109/LSENS.2018.2865883

Rafael R, Puyoo E and Malhaire C (2017) Piezo-tunnel effect in $\mathrm{Al} / \mathrm{Al}_{2} \mathrm{O}_{3} / \mathrm{Al}$ junctions elaborated by atomic layer deposition. J Appl Phys 122:184501.

https://doi.org/10.1063/1.4994163

Schlicke H, Rebber M, Kunze S, and Vossmeyer T (2016) Resistive pressure sensors based on freestanding membranes of gold nanoparticles. Nanoscale 8:183.

https://doi.org/10.1039/C5NR06937H

Su M, Li F, Chen S, Huang Z, Qin M, Li W, Zhang X and Song Y (2016) Nanoparticle Based Curve Arrays for Multirecognition Flexible Electronics. Adv Mater 28:1369.

https://doi.org/10.1002/adma.201504759

Tolvanen J, Hannu J and Jantunen H (2018) Stretchable and Washable Strain Sensor Based on Cracking Structure for Human Motion Monitoring. Scientific Reports 8:13241.

https://doi.org/10.1038/s41598-018-31628-7

Xiao S Y, Che L F, Li X X and Wang Y L (2008) A novel fabrication process of MEMS devices on polyimide flexible substrates. Microelectronic Engineering 85:452.

https://doi.org/10.1016/j.mee.2007.08.004

Zhu L and McNamara S (2015) Low Power Tunneling Current Strain Sensor Using MOS Capacitors. J Microelectromechanical Syst 24:755.

https://doi.org/10.1109/JMEMS.2014.2351778 
Figure 1. a) Elaboration process of a Metal/ $/ \mathrm{Al}_{2} \mathrm{O}_{3} / \mathrm{Metal}$ junction. b) Current density as a function of the applied electric field measured on a $\mathrm{Pt} / \mathrm{Al}_{2} \mathrm{O}_{3} / \mathrm{Al}$ junction. Inset: schematic representation of a Pt/Al $\mathrm{A}_{3} / \mathrm{Al}$ junction integrated on a thermally oxidized Si substrate.

a)
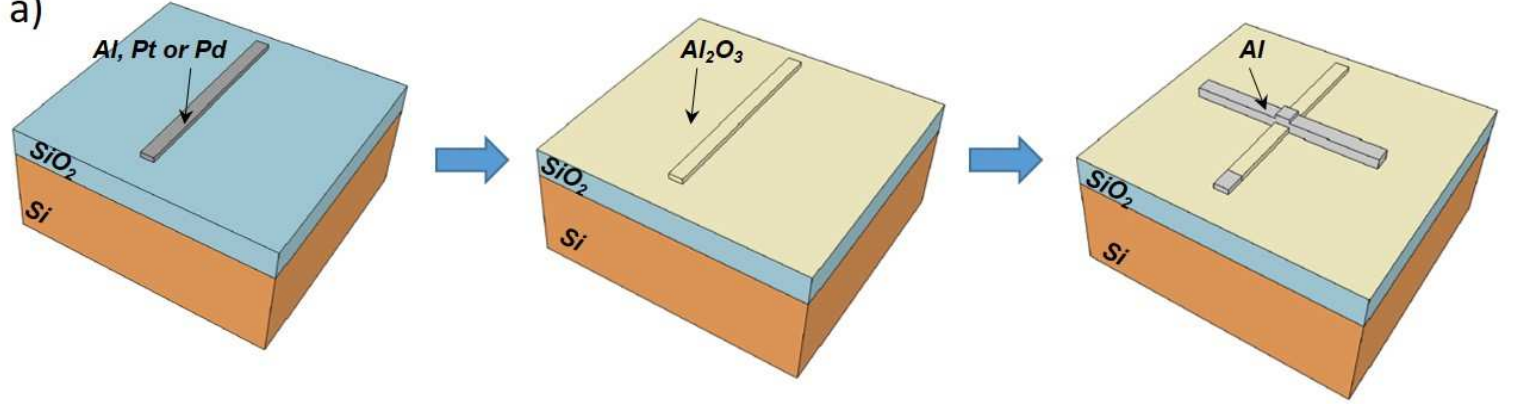

b)

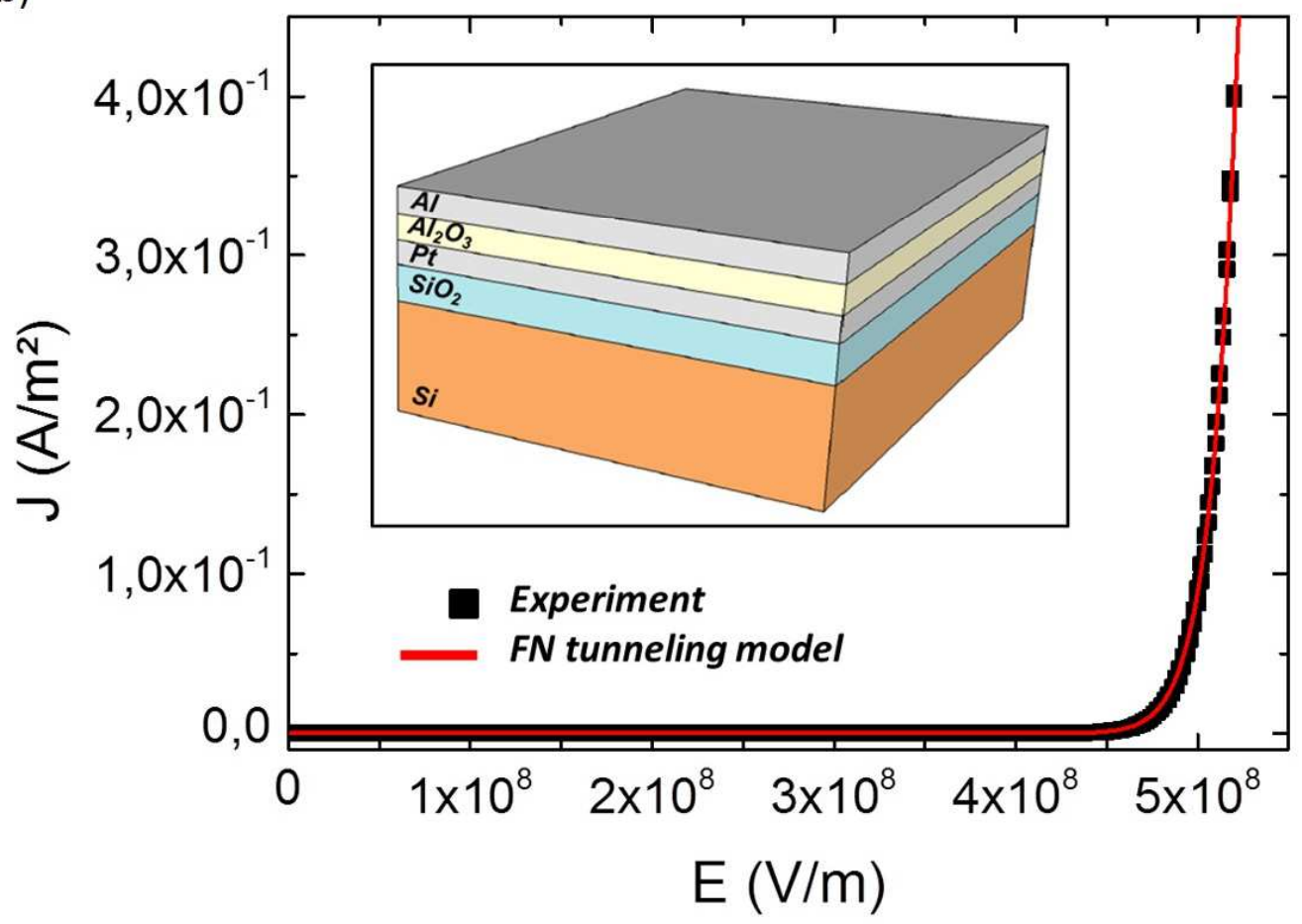


Figure 2. Gauge factors measured on six different junctions as a function of the no-load current level for both top and bottom injections.

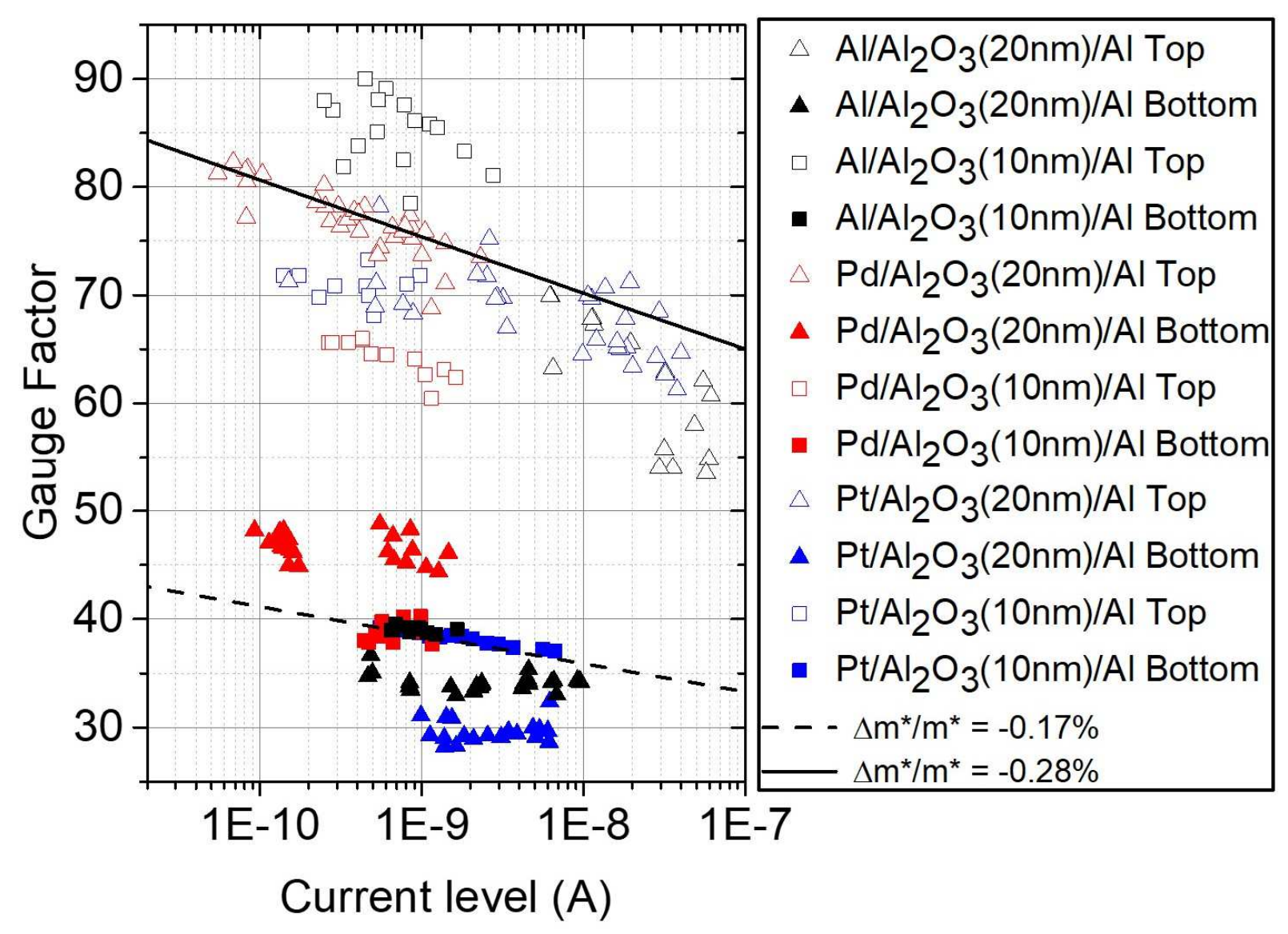


Figure 3. a) Laser-cut polysilicon shadow masks used to define the layout of bottom a) and top b) electrodes. c) Photograph of seven Metal/Oxyde/Metal junctions integrated on a $75 \mu \mathrm{m}$ thick polyimide substrate. d) Cross section view of the elaboration process.

a)

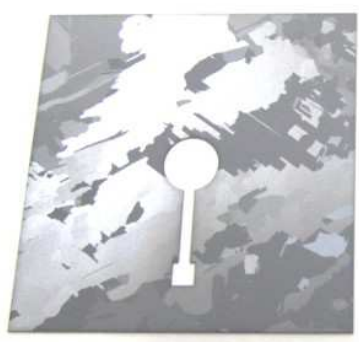

b)

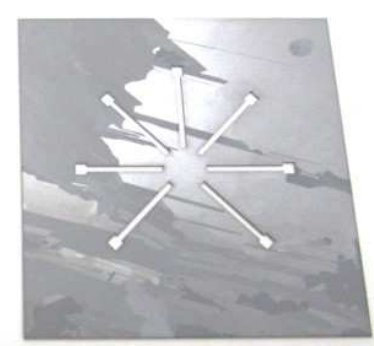

c)

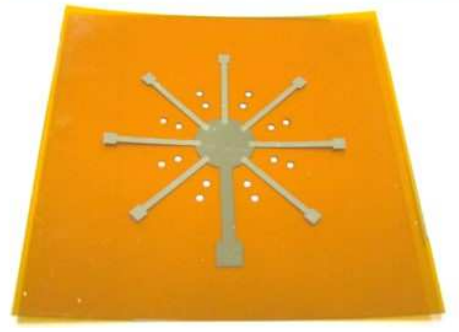

d)
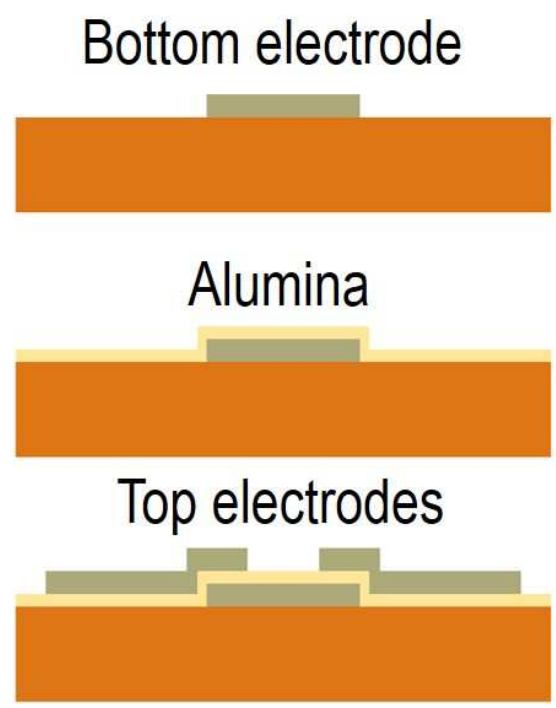

Figure 4. Photographs of the Fused Filament Fabrication process realized on the backside of a polyimide film.
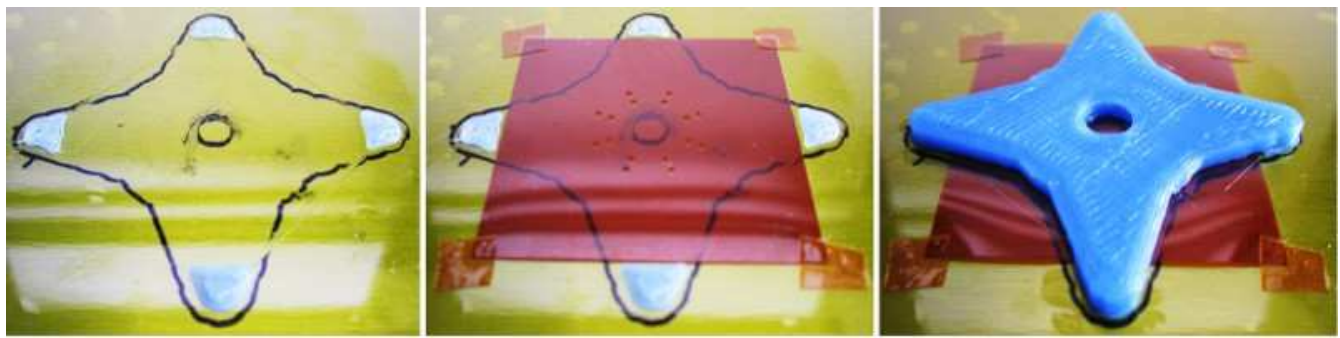
Figure 5. a) Response of the sensor for different pressure steps ranging from 50mbar to $850 \mathrm{mbar}$; b) Relative variation of current with respect to the applied differential pressure. Inset: photograph of the pressure sensor integrated on plastic.

a)

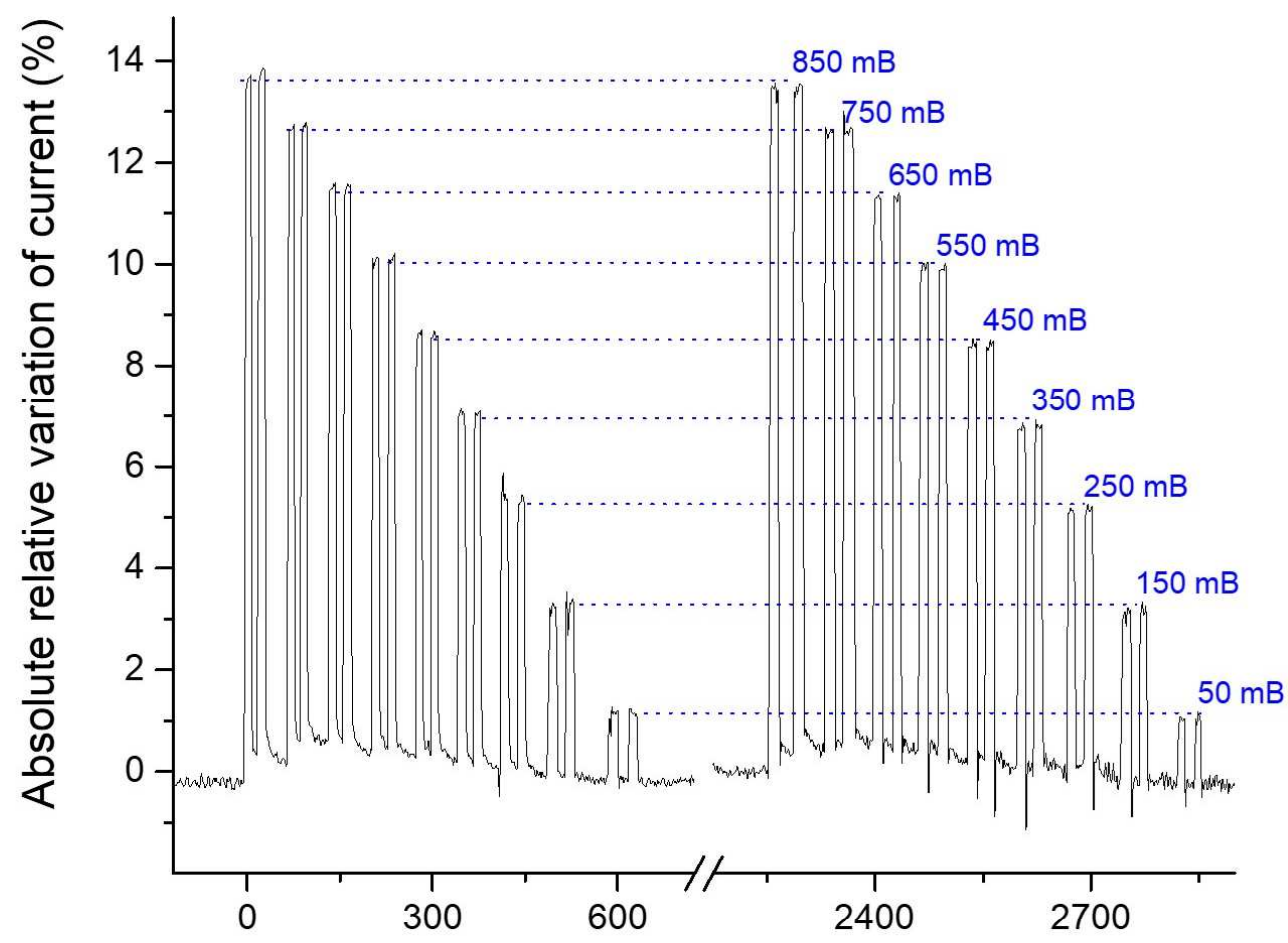

b)

Time (s)

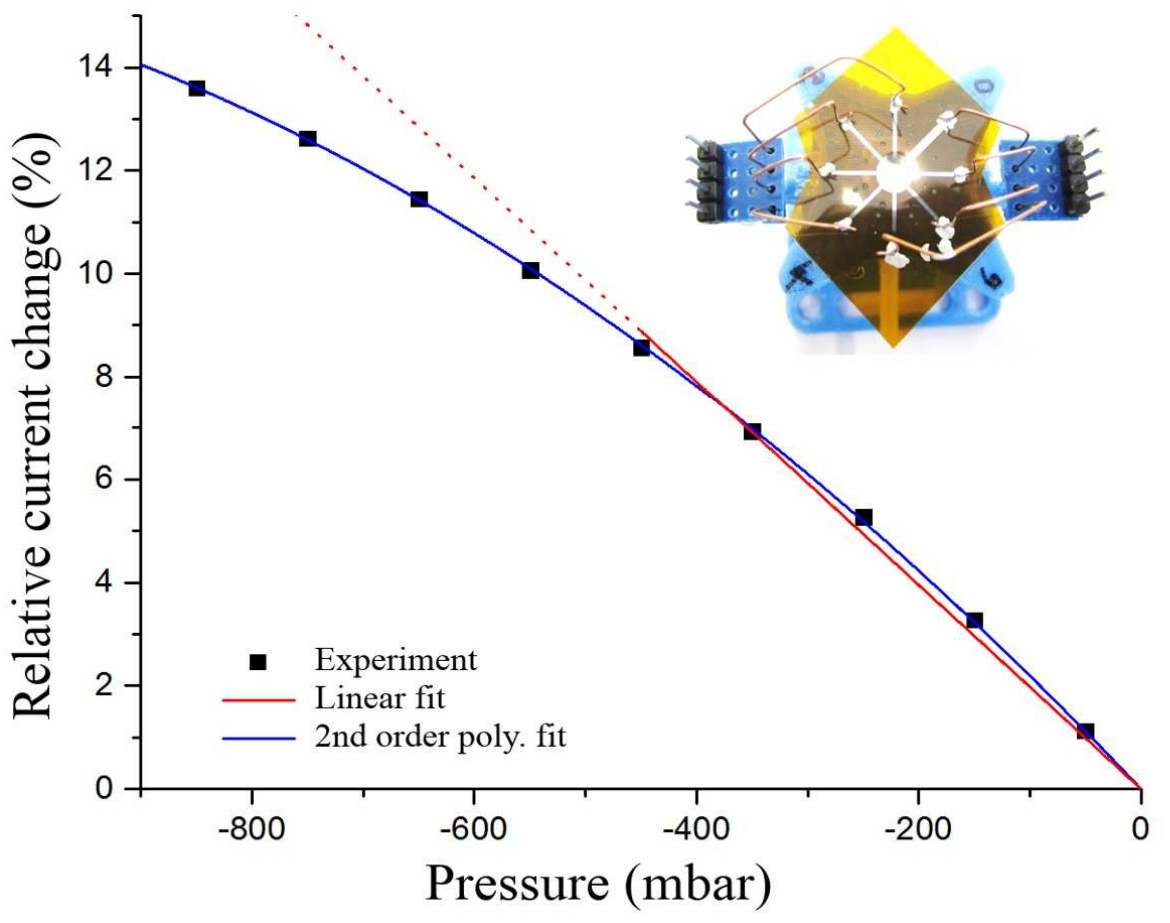


